\title{
Characteristic Features of the Value-Semantic Sphere of Students with Various Attitudes to Past Experience
}

\author{
Natalia Komerova ${ }^{1, *}$, Galina Zvezdina ${ }^{1}$, Marina Elagina $^{1}$, and Ekaterina Nemchenko ${ }^{1}$ \\ ${ }^{1}$ Don State Technical University, Gagarin sq., 1, 344003 Rostov-on-Don, Russia
}

\begin{abstract}
The article is devoted to the study of the assessment of past experience in connection with the peculiarities of the valuesemantic sphere of students aged 19 to 21 years. It presents a comparative analysis of the results of the study of students of the Faculty of Psychology with various attitudes to past experience, by dividing them into two groups with a positive and neutral-negative assessment of past experience. The analysis is carried out on the basis of a number of techniques that allow one to see the substantive aspects of the value-semantic and motivational spheres of students. The study of value orientations in groups was carried out, differences in the level of significance of the studied values for the respondents were revealed. The study of terminal values showed that a happy family life is the main one for the group with a positive attitude to the past, while for the second group health, love and self-confidence are more important. With regard to instrumental values, it was revealed that a group with a positive assessment of the past considers responsibility as the most important, while the other emphasizes honesty. It was found out that groups with a positive attitude to past experience are distinguished by greater satisfaction with the results of life in the present period of time, meaningful life process and a higher level of motivation.
\end{abstract}

\section{Introduction}

The life path of a person is full of events that are determined by external and internal factors, some of which become fateful, some are simply "ordinary". Evaluation of past events, attitude towards one's experience becomes a part of the personality's identity, participates in the formation of attitude towards oneself, self-concept. During life, a person repeatedly reconsiders their attitude to past experience, and, depending on this analysis, makes a conclusion about their success, solvency, satisfaction with life. The motivational

\footnotetext{
* Corresponding author: zhukova-teatr@yandex.ru
} 
and value-semantic sphere of the personality reflects the direction of the personality's development, their relation to the time of life in general.

Young people who have just begun their adult life often go through an identity crisis, which is characterized by the need to make a number of life choices and decisions that affect both personal (search for oneself, the need for intimacy, expansion of social roles) and professional self-determination [1]. The basic life values, meanings and attitudes of young people are not specific and idealized. In the case of the formation of an inadequate identity, the development of a young person can follow the path of destructiveness, a fear of close interpersonal relationships, a blurring of the sense of time, an inability to build longterm life plans, and a fear of failure [2]. In this transitional life period, when there is still little experience of independent life, the influence of past experience on behavior patterns, ideas about the present and the future can be very great. The study of achievement motivation, life values and goals of students with different subjective assessments of past experience is relevant because it can determine the future development of a personality, its aiming.

Studies of subjective experience and perception of a person's life span are found in the works of both domestic and foreign authors, such as S.L. Rubinstein, K.A. AlbuhanovaSlavskaya [3], E.I. Golova-ha, V.I. Kovalev, K. Levin, J. Nyutten, F. Zimbardo, L.A. Regush [4] and others.

The relationship between the problem of psychological time and gender and age characteristics is clearly defined in the works of L.V. Borozdina, I.A. Spiridonova, E.N. Kuteeva [5], the determining influence of relationships over time on overcoming stressful situations (L.I. Antsyferova, F.E. Vasilyuk, K. Muz-dybaev), the influence of time perception on the formation and change of the self-concept (I.S. Kon, V.S. Mukhina, L.A. Regush).

According to K. Levin, it is necessary to consider a person's life in the present tense taking into account his past experience and the prospects for his development, so he introduced the concept of "time perspective". "Time perspective is the inclusion of the future and the past, the real and ideal plan of life in the plan of the moment." The psychological past of a person is a part of a given moment, a certain psychological field, one of the dimensions of space, which helps expand the idea of oneself [6]. Determination of the influence of the past, present and future on the behavior of a person is due to the fullness of the content of each time period. F. Zimbardo claims that the individual sense of time is one of the most powerful factors influencing the thoughts, feelings and actions of a person. A person exists in the space of three subjective psychological zones: past, present and future [7]. Each of these time zones is detailed depending on cultural characteristics, beliefs, value systems and life meanings, memories and life experiences. Thus, each personality has its own temporal aiming, which consciously or unconsciously influences the life decision-making [8].

The temporal field of the personality - a system of personally significant past, present and future - is conditioned by such factors as age, meanings and values. The connection between the past, the future and the present in consciousness is formed into a picture of the "life path" (S. L. Rubinstein, K. A. Al-Bukhanova-Slavskaya [9])

Features of the value-semantic sphere of personality are described in detail in the works of I.V. Abakumova [10], M. Rokich, D.A. Leontyev, S.S. Bubnova, V.N. Druzhinin, J.L. Kolominsky, A.V. Seryogo, V. Frankl, M.S. Yanitskiy, V.A. Poison.

Currently, the system of personal values determines the meaning of life and aspirations of the individual. Changes in the structure of personal values reflect the process of human development. The meaning of personality crises in maturity is a consequence of changes in value orientations and semantic content [11]. In the process of personality development, values undergo changes, replacing each other, changing not only their content, but also the 
leading role in human life. Revaluation and transformation of values is an invariable part of personality development. Acquiring new social roles forces a person to re-evaluate the events of his life. According to R.S. Nemov [12], this reflects the main stage of personal development in adulthood, following adolescence. Therefore, the study of the relationship between the assessment of the past experience of young people and the value-semantic structure of the personality is very relevant for analysis.

\section{Purpose and research issues}

In order to study the attitude of students to past experience, as well as the peculiarities of their motivational and value-semantic sphere, we conducted an empirical study.

The purpose of this research is to identify the features of the motivational and valuesemantic spheres of students with different subjective assessments of their past experience.

Research hypotheses are as follows:

- value-semantic and motivational spheres of personality among students with different subjective assessments of their past experience may differ;

- students with a positive subjective assessment of past experience may have higher indicators of life satisfaction, the level of motivation, and more formed ideas about the life path.

To achieve this goal and confirm the hypotheses put forward, we have chosen the following methods:

1. "Time perspective questionnaire" by F. Zimbardo.

2. "Unfinished sentences about the past" questionnaire as modified by G.P. Zvezdina, N.E. Komerova on the basis of Sachs Levy's "Unfinished sentences" method.

3. "Motivation to achieve success or fear of failure" by A. Rean.

4. "Value orientations" methodology by M. Rokich.

5. "Test of Life-Meaningful Orientations (LMO)" D.A. Leontyev.

As methods of mathematical statistics U-Mann Whitney test was used. Statistical analysis was performed using the STATISTIKA-10 package.

Don State Technical University was the empirical base of the research.

The object of the research were 45 second-year students aged 18 to 21 years, majoring in psychology.

\section{Measurements and data processing}

The research was carried out during 2 months in four stages: scientific - theoretical, organizational, psychodiagnostic and ascertaining.

To determine the differences in the subjective assessment of past experience, the "Questionnaire of the time perspective" methodology by Philip Zimbardo was used, the purpose of which is to study the system of personality's relations to the time continuum. The research results are displayed on five scales: "Negative Past", "Positive Past", "Hedonistic Present", "Fatalistic Present" and "Future". Within the framework of this article, we want to focus on the "positive past" scale, which characterizes the "warm, sentimental attitude towards the past." According to the results revealed in the group of students, $48.9 \%$ (22 people) of the respondents assessed their past as clearly "positive" (Sub-group 1), while the values on this scale for $51.1 \%$ (23 people) of the respondents were within the range average, or below average (Sub-group 2). This scale became the basis for dividing the group of subjects into two subgroups for comparing the features of the motivational and value-semantic spheres among students with a high positive assessment of past experience and students who rated it as neutral or negative. 
The presented results show that the subjects from Sub-group 1 have the mean values on the "negative past" scale less distinctive and more distinctive on the "positive past" scale, which may indicate a positive assessment of the past experience, as well as the presence of an attitude to receive pleasure in the present ("hedonistic present"), compared to the second Sub-group. Therefore, such a division into sub-groups can be considered acceptable.

\section{Results}

In her research according to the methodology of questionnaire "Unfinished sentences about the past" as modified by G.P. Zvezdina, N.E. Komerova asked the respondents to answer three questions about the past, with the need to supplement the sentences with the first that comes to mind without hesitation. The distribution of data was carried out by grouping similar responses of respondents into three categories: negative assessment, neutral assessment, positive assessment. Table 2 presents the units of analysis for combining responses.

Table 1. Units of analysis for grouping respondents' answers into groups using the "Unfinished sentences about the past" method

\begin{tabular}{|l|l|l|}
\hline Options for questions & Units of analysis & Possible answers \\
\hline The past is ... & negative assessment & $\begin{array}{l}\text { cargo; remnants; something that is better not to } \\
\text { remember }\end{array}$ \\
\hline & neutral assessment & $\begin{array}{l}\text { experience; what has passed; memories; } \\
\text { memory }\end{array}$ \\
\hline & positive assessment & $\begin{array}{l}\text { basis for development, warm memories, history } \\
\text { to remember }\end{array}$ \\
\hline I remember the past ... & negative assessment & $\begin{array}{l}\text { with bitterness; more often than you would like; } \\
\text { with anxiety, with fear }\end{array}$ \\
\hline & neutral assessment & sometime; not so often; don't remember \\
\hline & positive assessment & $\begin{array}{l}\text { with warmth; with smile; with thanks; easily; } \\
\text { well; with joy }\end{array}$ \\
\hline & negative assessment & $\begin{array}{l}\text { few positive colors; regrettable; complicated; } \\
\text { difficult }\end{array}$ \\
\hline & neutral assessment & usual; an important lesson; instructive \\
\hline & positive assessment & worthy; bright; good shim; useful; happy \\
\hline
\end{tabular}

A neutral assessment of the past is associated with experience, or with time that has already passed. A negative perception of the past reflects unpleasant memories, negative emotions, difficult periods of life, unwillingness to refer to these memories. Assessing the past in a positive way is assessed as a pleasant memory, as a resource that can be used in difficult situations of life [13].

The data obtained are calculated as a percentage of the total number of respondents and help see the respondents' assessment of past experience in quantitative terms.

Table 2. Data from the content analysis of the methodology "Unfinished sentences about the past"

\begin{tabular}{|l|l|l|l|l|l|l|l|l|l|}
\hline $\begin{array}{l}\text { Group } \\
\text { name }\end{array}$ & \multicolumn{2}{|l|}{ Past is ... } & \multicolumn{3}{l|}{ I remember the past ... } & \multicolumn{3}{l|}{ My past was ... } \\
\hline & $\begin{array}{l}\text { negative } \\
\text { assessm } \\
\text { ent, } \%\end{array}$ & $\begin{array}{l}\text { neutral } \\
\text { assessm } \\
\text { ent, } \%\end{array}$ & $\begin{array}{l}\text { positive } \\
\text { assessm } \\
\text { ent, } \%\end{array}$ & $\begin{array}{l}\text { negative } \\
\text { assessm } \\
\text { ent, } \%\end{array}$ & $\begin{array}{l}\text { neutral } \\
\text { assessm } \\
\text { ent, } \%\end{array}$ & $\begin{array}{l}\text { positive } \\
\text { assessm } \\
\text { ent, } \%\end{array}$ & $\begin{array}{l}\text { negative } \\
\text { assessm } \\
\text { ent, \% }\end{array}$ & $\begin{array}{l}\text { neutral } \\
\text { assess } \\
\text { ment, } \%\end{array}$ & $\begin{array}{l}\text { positiv } \\
\text { e } \\
\text { assess } \\
\text { ment, } \%\end{array}$ \\
\hline $\begin{array}{l}\text { Sub-group } \\
1\end{array}$ & 4.55 & 86.36 & 9.09 & 4.55 & 18.18 & 68.18 & 18.18 & 22.73 & 59.09 \\
\hline $\begin{array}{l}\text { Sub-group } \\
2\end{array}$ & 8.70 & 73.91 & 13.04 & 30.43 & 30.43 & 34.78 & 34.78 & 39.13 & 21.74 \\
\hline
\end{tabular}


In sub-group 1, a positive assessment of the past is clearly expressed in $68 \%$ of the subjects, and only $4.55 \%$ gave negative answers to the sentence "I remember the past ...". Also, to the sentence "My past was ..." $59.09 \%$ of subgroup 1 gave a positive assessment, while in sub-group 2 only $21.74 \%$ named answers with a positive connotation.

We will analyze the data obtained using the methods of studying the motivational and value-semantic spheres of the personality. To analyze the level of motivation of respondents, the "Motivation to achieve success and fear of failure" methodology was used, consisting of 20 statements that must be confirmed or refuted. As a result, average results were obtained in terms of motivation for achieving success among the selected groups of students.

Since, within the framework of this methodology, results over 12 points indicate motivation to achieve success, both subgroups of students are, on average, motivated to achieve success, but in subgroup 1, with a positive attitude to the past, the level of motivation is slightly higher.

The "Test of meaningful life orientations" methodology consists of twenty pairs of opposite statements, the respondents choose the degree of fidelity of the statement [14]. The results are distributed according to five main scales: "Goals in life" reflects the formation of the personality's ideas about goals and basic life guidelines; The "process of life" is an indicator of satisfaction with the present; "Result of life" determines the degree of achievement of life goals in a given time period; "Locus of I-control" summarizes the idea of oneself as a person capable of controlling their life and determining the degree of this control; "Locus of Life control" gives an understanding of the controllability of life. As a result of the study, the following data for subgroups were obtained.

Table 3. Comparative results of the study on the "Test of meaningful orientations" methodology in selected groups of students

\begin{tabular}{|l|l|l|l|l|l|l|}
\hline Group name & $\begin{array}{l}\text { Life } \\
\text { goals }\end{array}$ & $\begin{array}{l}\text { Life } \\
\text { process }\end{array}$ & Life result & $\begin{array}{l}\text { Locus of I } \\
\text { control }\end{array}$ & $\begin{array}{l}\text { Locus of Life } \\
\text { control }\end{array}$ \\
\hline Sub-group 1 & 34.7 & 31.4 & 28.3 & 22.9 & 35.8 & \\
\hline Sub-group 2 & 30.9 & 28.1 & 24.08 & 21.3 & 31.6 & \\
\hline $\begin{array}{l}\text { U-Mann-Whitney } \\
\text { criterion, Uemp }\end{array}$ & 174.5 & 199 & 144.5 & 201 & 161.5 & \\
\hline
\end{tabular}

On all scales at the level of average values, the indicators of life-meaning orientations in sub-group 1 are higher than in subgroup 2, which allows us to speak of a greater meaningfulness of life, a clearer idea of the goals of life, and the feeling that the life path is built in accordance with one's own desires. As a result of mathematical processing of the data using the U-Mann-Whitney criterion, it was revealed that statistically significant differences are observed between subgroups on the scale "Life Result" 1 is higher than that of the second subgroup. Also, the data on the scales "Goals in life" and "Locus of Life control " in subgroup 1 are higher than those of subgroup 2, which indicates a clearer idea of their future, greater awareness and a sense of control over what is happening in their life. However, when carrying out a statistical analysis, the values of these scales fell into a zone of uncertainty, which may indicate a tendency towards the significance of differences, which may appear in a larger sampling [15].

To identify the content components of the value-semantic sphere of students, the "Value orientations" methodology by M. Rokich was used. This methodology is composed of two blocks representing terminal and instrumental values that are associated with personal life, professional self-realization, communication, character traits, acceptance of oneself and others, etc. [16]. For each block, 18 most widespread values are identified. The respondents were asked to rank the values from the most significant to the least. As a result of the study, the following data were obtained for analysis. 


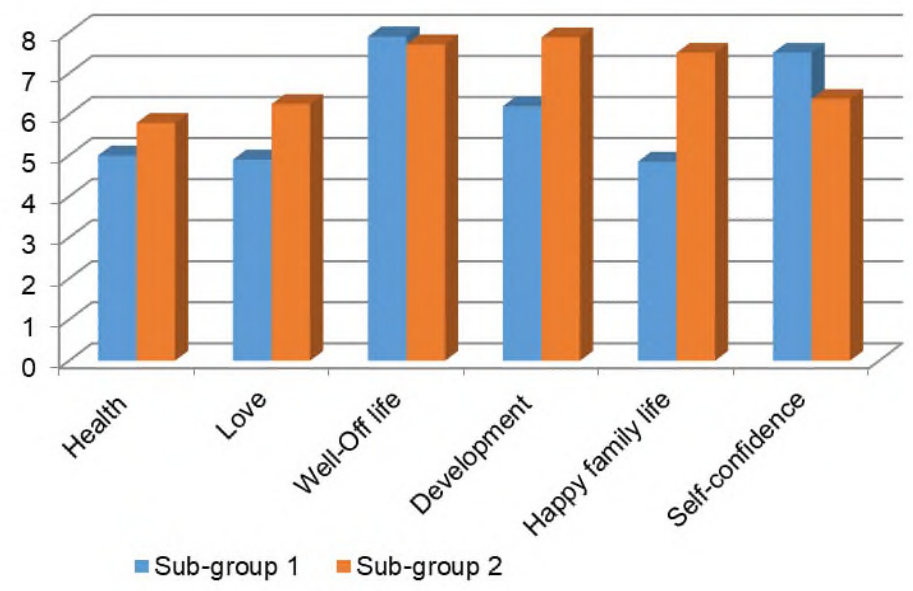

Fig. 1. Results according to the "Value orientations" methodology by M. Rokich. Terminal values.

The figure shows the most important value orientations in sub-groups. According to the results obtained, the main terminal values in Subgroup 1 were: happy family life (1), love (2), health (3), development (4), self-confidence (5), while in subgroup 2: health (1), love (2), self-confidence (3), happy family life (4), well-off life (5). The values that fall into the priority group are the same, but the main difference is in the ranking of their importance. For example, self-confidence for subgroup 2, where the assessment of past experience is neutral or negative, turned out to be more important [17]. The "happy family life" indicator for subgroup 1, where the assessment of past experience is positive, is in first place, and for subgroup 2, only in the 4th. Although the value of "love" has the same meaning for both subgroups. The revealed differences show that for subgroup 1, relationships with significant relatives are the most important, while subgroup 2 is focused primarily on oneself, health, independence, self-confidence, and only after those on happy family relationships. The data obtained indicate the presence of differences in the characteristics in the value-semantic sphere of respondents with different assessments of past experience. Table 6 shows the results of the distribution of instrumental values between sub-groups.

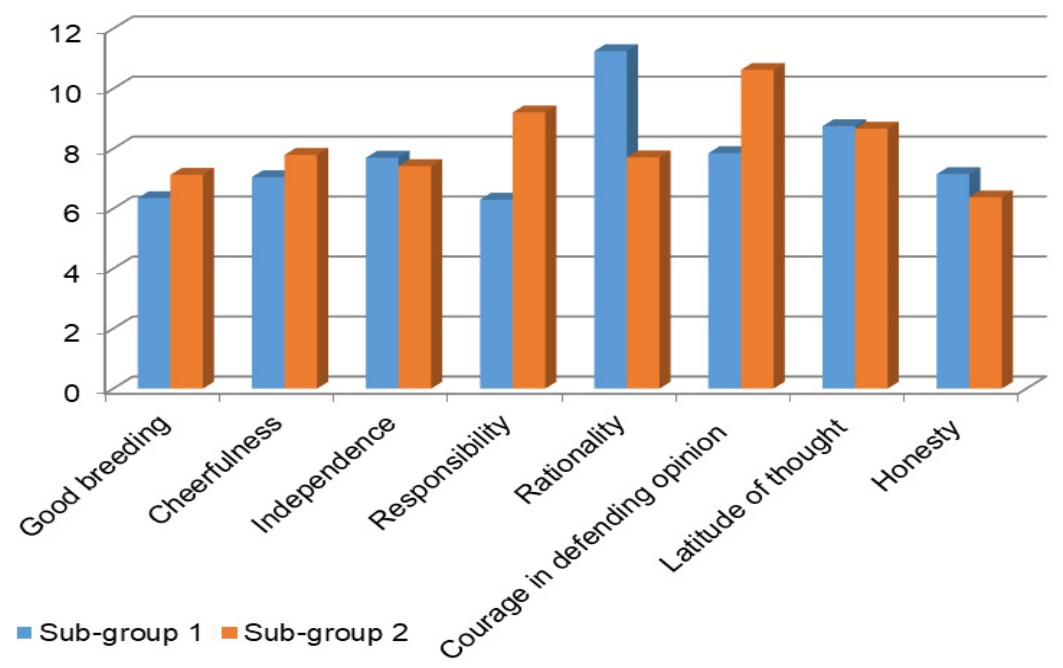

Fig. 2. Results according to the "Value orientations" methodology by M. Rokich. Instrumental values 
So, for Subgroup 1 with a positive assessment of past experience, responsibility (1) takes the first place, followed by good manners (2), cheerfulness (3), honesty (4), independence (5). The data for Subgroup 2 are as follows: honesty (1), good breeding (2), independence (3), rationalism (4), cheerfulness (5). We see that the distribution of leading instrumental values has interesting differences [18]. For example, the most important quality for Subgroup 2 is honesty, while for Subgroup 1 it is responsibility. We would like to note that responsibility presupposes obligations to others and presupposes their fulfillment, and honesty is necessary both in dealing with others and in relation to oneself.

\section{Discussion}

According to the results of the study, the value-semantic and motivational sphere of a young person's personality has certain characteristics depending on the subjective assessment of past experience as positive or negative. We have obtained data that the general level of satisfaction and meaningfulness of life in a group with a positive assessment of past experience is higher. The presence of features is also evidenced by the studies of foreign authors, "value priorities predict satisfaction with life both directly and indirectly through time perspectives" [Sword, RM, Sword, KM, Brunskill, SR, Zimbardo, PG, 2014] ; time perspective is associated with a number of important results in various spheres of life (e.g., health, education, welfare) [Baird, H. M., Webb, T. L., Sirois, F. M., Gibson-Miller, J., 2020]; personal values and time perspective are important predictors of subjective well-being [Borghi, Anna \& Barsalou, Lawrence, 2021]; an increasing interest in the construct of time perspective (TP), describing dispositional tendencies to use, and overuse particular time horizons, is observed in psychological research literature [Stolarski, M, Zajenkowski, M, 2020]; the value construct remains relevant in the research space, opens up a palette of values of different groups of the population [Pishchik, V, 2020].

Since this study was conducted within the framework of one age category of respondents, and there was no division of groups by gender, it becomes necessary to further study the relationship between attitudes toward one's past and the value-semantic sphere of a person with an extended sampling.

\section{Conclusions}

Summarizing the results of the study, we can conclude that the subjective attitude to the past and its assessment has an impact on the real life of the individual, their idea of "significant".

Differences in life-meaning orientations and value preferences were revealed among the selected groups of students with different levels of subjective attitude to their past.

The sub-group with a positive assessment of past experience has a higher level of motivation to achieve success, is more satisfied with the present, and has certain goals for the future. This group of students defines the past as a basis for development, a history that needs to be remembered; treats their past as bright, warm, happy; memories of the past are warm, grateful, joyful.

In the system of values, the first place was taken by a happy family life, and responsibility was the leading instrumental value, it includes the willingness to take responsibility for one's actions and make decisions about oneself and one's future.

The sub-group with a neutral and negative attitude towards the past also, having high results in terms of the level of motivation, the level of meaningfulness in life, is statistically significantly less satisfied with the passed segment of the life path. The main values are health, love and self-confidence, and honesty is the instrumental value, which, in our 
opinion, also testifies in favor of the hypotheses put forward concerning the relationship between past experience and personal value orientations, and the presence of differences. Self-confidence is formed in the process of life and the attitude to the past plays a fundamental role here. We believe that the results of the study confirm the hypotheses put forward, and also provide a basis for setting new research tasks with an expanded sampling, within the framework of gender differences, age periods of a person's life and ethnoconfessional differences.

\section{References}

1. O.P. Tsaritsentseva, T.A. Lipskaya, Structural and substantive features of the attitude to the time of students with different levels of optimism, Ped.Rev. 6(28) (2019) .DOI: 10.23951 / 2307-6127-2019-6-191-201

2. E.N. Kuteeva, Emotional attitude to time in adolescence, KPZH, 4(117) (2016)

3. T.V. Koshelskaya, The content of the concept "Temporary perspective of personality" Innovation science, 1-2(13) (2016)

4. A.M. Borghi, L. Barsalou, Perspective in the conceptualization of categories. Psychologi-cal Research (2019)

5. I.V. Abakumova, Smyslodidaktika: a textbook for masters of pedagogy and psychology Federal Agency for Education of the Russian Federation, State. educational institution of higher. prof. education "Southern Federal University", 385 (Rostov-on-Don, Credo, 2008)

6. E.A. Medovikova, I.S. Morozova, Substantive characteristics of the temporal perspective of the personality of university students, Russian Journal of Education and Psychology, 10(44) (2014) DOI: 10.12731 / 2218-7405-2014-12-19

7. E.U. Pochtareva, Value-semantic sphere of personality: essence, determinants, mechanisms of development, Bulletin of Perm University, Philosophy. Psychology. Sociology, 4 (2017)

8. S.J. Kim, H.J. Kim, K. Kim, Time Perspectives and Delay of Gratification - The Role of Psychological Distance Toward the Future and Perceived Possibility of Getting a Future Reward. Psychol Res Behav Manag, 13, 653-663 (2020)

9. N.S. Pavlova, E.A. Sergienko, Quality of life and temporal perspective at the stage of late ontogenesis, Bulletin of Kostroma State University. Seria: Pedagogy. Psychology. Sociokinetics, 2 (2020) DOI: 10.34216 / 2073-1426-2020-26-2-47-55

10. H.M. Baird, T. L. Webb, F.M. Sirois, J. Gibson-Miller, Understanding the effects of time perspective: A meta-analysis testing a self-regulatory framework. Psychological Bulletin. Advance online publication (2020) DOI: 10.1037 / bul0000313

11. L.K. Barber, D.C. Munz, P.G. Bagsby, M.J. Grawitch, When does time perspective matter? Self-control as a moderator between time perspective and academic achievement. Personality and Individual Differences, 46, 250-253 (2009)

12. M. Stolarski, M. Zajenkowski, K.S. Jankowski, K. Szymaniak, Deviation from the balanced time perspective: A systematic review of empirical relationships with psychological variables, Personality and Individual Differences, 156 (2020) https://doi.org/10.1016/j.paid.2019.109772.

13. O.N. Popova, The problem of balancing the temporal perspective of a personality, Siberian Journal of Psychology, 66 (2017) DOI: 10.17223 / 17267080/66/2 
14. R. Zena, Mello: A construct matures: time perspective's multidimensional, developmental, and modifiable qualities. Research in Human Development. San Francisco State University, 16(2), 93-101 (2019)

15. R.M. Sword, K.M. Sword, S.R. Brunskill, P.G . Zimbardo, Time Perspective Therapy: A New Time-Based Metaphor Therapy for PTSD, Journal of Loss and Trauma, 19(3), 197-201 (2014) DOI: 10.1080 / 15325024.2013.763632

16. A. Borghi, L. Barsalou, Perspective in the conceptualization of categories. Psychological Research (2021) DOI: 10.1007 / s00426-019-01269-0.

17. V. Pishchik, The uniqueness of values and personal traits of Generation $Z$ students in the innovative educational space of the southern region of Russia. Innovative Technologies in Science and Education (ITSE-2020). E3S Web Conf. 210, 18035 (2020) https://doi.org/10.1051/e3sconf/202021018035

18. J. Witowska, M. Zajenkowski, M. Wittmann, Integration of balanced time perspective and time perception: The role of executive control and neuroticism, Personality and Individual Differences, 163 (2020) https://doi.org/10.1016/j.paid.2020.110061. 